\title{
Problem oriented Research-style teaching methods for engineering education
}

\author{
Xiong Wei \\ School of Electrical Engineering and Renewable Energy \\ Three Gorges University \\ Yichang, China \\ xiong_wei66@163.com
}

\author{
Li Anming;Su Shiwei \\ School of Electrical Engineering and Renewable Energy \\ Three Gorges University \\ Yichang, China \\ 21864436@qq.com
}

\begin{abstract}
In view of the engineering course the characteristics of content abstract, theoretical depth, strong practicality. Study how to combine knowledge of problem solving process one by one to set up the teaching link. From knowledge review, new knowledge introduction, knowledge formed on cohesion and summarizes the teaching process. Avoid process sequencing and analysis of key nodes of teaching. So as to improve the students' interest in teaching, training students' learning habits in the new mode.
\end{abstract}

Keywords-engineering education; Research-style teaching; Problem; Course features

\section{INTRODUCTION}

For classroom theory teaching is the main form of university education, the students during the whole university mainly through learning knowledge in the classroom. Students in the classroom theoretical study degree for students after graduation whether further study or enter the jobs are very important, so teachers of university teaching and theory attaches great importance to the classroom teaching effect. Many teachers for the classroom teaching reform and teaching method have been studied in many. Through the application of teaching means, such as the application of multimedia in the teaching; [1] through the study of teaching methods to improve teaching effect; [2,3] And start from the teaching content of course teaching. [4,5] The middle of the 20th century, American biologist and educator, a professor at the university of Chicago in 1961 in the memorial lecture at Harvard University for the first time put forward the "to explore the science of teaching". In the United States began exploratory teaching steps from now on. Since the $1980 \mathrm{~s}$, countries around the world generally attach importance to the cultivation of student's innovation ability, the study of exploratory teaching also has the development of the update, Britain, Australia, Japan support inquiry-based teaching. Inquiry teaching is introduced into our country in the $1990 \mathrm{~s}$, has become a hot spots of the teaching method reform [6]. In this paper it mainly study in exploratory teaching, how to set up the organization to question teaching link.

\section{RELATED BASIC CONCEPTS}

One that served as the President of Harvard University for many years, the university is the core of education affairs "education goals" and "education method", "really happened that influences the quality of education in the university classroom, teachers and students interactive teaching situations." "Exploratory method" as a stress based on the problems and facing reality, highlight the independent inquiry, cooperation, interaction of a main interactive learning method, is refers to the students in learning, teachers by giving them some examples and problems, let the student through the way such as reading, thinking, discussion, listening to explore independently, to find and master a method of the corresponding conclusion. In the process of inquiry teaching, the students' subject status, independent ability has been strengthened. "Engineering education" means to aim at training future engineers, mainly engineering course, closely related engineering application way of education, mainly refers to some engineering. "Problem oriented" is in the design of teaching links, whether to review the old knowledge, importing new knowledge, establishing contact between old and new knowledge, new knowledge, the cohesion between the outstanding or conclusion, were exhibited in the form of a question, and to issue or case in which agents and highlight the teaching content and target.

\section{THE CHARACTERISTICS OF THE ENGINEERING TEACHING}

Engineering curriculum has its inherent characteristics. Part of the engineering course has the characteristics of strong abstractness. Many courses in engineering disciplines are in the physical control, such as motors, such as transformers, students in practice and practice can be a real object to watch. But the electromagnetic field is invisible, and can not be touched. In the middle school, it is only a preliminary introduction to the students, but in the University, the theory is deeper, and the abstract thinking is more demanding. So in the course of engineering electromagnetic fields, is not easy with the students to explain clearly, usually through a large number of examples, the velocity field can see a car on the road running, the height field can be in usually go mountain climbing, everyone's altitude and so on. And then explain to the students through some illustrations, as shown in figure 1. It is a single straight current magnetic field around the conductor. If there is 
no picture, the students are not easy to imagine what it is like. Again, such as "high voltage technology", introduces the theory of gas breakdown, the formation of the electron avalanche, the development of the electron avalanche, lingers formation and so on students rely on their own imagination, as well as some static pictures. So in this kind of multimedia demonstration and computer simulation in teaching becomes more important.

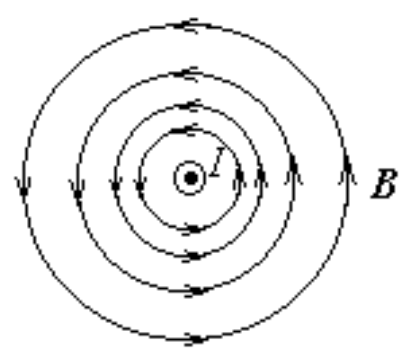

Fig 1. Single power straight wire around the magnetic field

Part of the engineering course has the characteristics of strong practicality, such as "motor learning", "power system automation devices", "power plant, the main electrical wiring" and so on. In this kind of course must be combined with actual project is more, the conditional case, show students field devices, look at the performance of the equipment. And understanding of the actual enterprise is how to design the electrical wiring diagram. These do not necessarily need to know students very deep. Only need a preliminary understanding, understand the theory can be profound.

And has the characteristics of strong theoretical part of the engineering courses, such as "power system analysis", basically a line for this type of course. Need teachers on the teaching unit 1 , step by step guide, let the students feel it's in every class, to improve the students' interest in learning. Of course a lot of engineering course is the characteristic of both aspects.

Due to the above characteristics of engineering courses, the need for targeted. With abstract, theoretical depth, but the formula is not much of the characteristics, such as the breakdown of the atmosphere, the pure text of the students is difficult to understand, and then you need to help teaching, to display images or video. And some other formulas are derived to calculate many of the courses, which may not be suitable for use in multimedia assisted instruction. And because of the practice of the curriculum, the characteristics of the actual engineering contact. Such as the introduction of insulators, transmission lines, lightning rod and other related knowledge, the use of multimedia display entity pictures, so that students know what the device is like, the students more easily contact with the actual deepen understanding. Anyway, sometimes if there is not much of the course, it can be used to compensate for the lack of this aspect.

\section{COMBINING WITH THE CHARACTERISTICS OF CURRICULUM SET UP QUESTIONS FOR THE GUIDE}

\section{A. Role of introduction}

Due to the characteristics of engineering courses, the students in class effect is not good, not deep understanding of the knowledge and the curriculum content lack of interest, and exercises in class and after class exercises plagiarism phenomenon serious, resulting in students in course of a pass rate is not high. So students per session before the course began, it has been the fear of difficulty, it has been in previous students there heard this course is how difficult, how many people did not pass. So through the introduction of the introduction, in form of a relaxed chat, lets the student understand the characteristics of this course, and know how to learn this course, so as to stimulate students' interest in learning, which is very important.

The introduction of the role of a large area is to develop students and this course related to the field of vision. And students talk about life in some of the examples, such as electromagnetic wave propagation, communication, electromagnetic shielding, and so on, so that students like listening to the story as well as to understand the relevant knowledge. Speak good introduction class teachers need in addition to familiar with the teaching content, especially reading magazines, literature, understand the latest developments, collecting a lot of data, good at expression play teaching art enrich the inner world, can stimulate students' enthusiasm for learning, to meet the thirst for knowledge, learn to generate curiosity.

Also to chat form and student exchanges previous students learn some amusing stories in this course, closer to the distance between the students, training and students between the feelings, let the students have certain understanding to the teaching habits of teachers, there is a great help for communication teaching behind the students in a relaxed gradually into the learning of this course.

\section{B. Establishment of problem}

In the design of the problem, should be targeted, love should be based on the teaching content, grasp the basic concepts and basic knowledge, and closely related to the center of the teaching material and the important and difficult. Teachers should be through this a series of question answer, connect, and introduce the emphases and difficulties of this class gradually. At the same time, puts forward the problem of the difficulty to moderate. Problem is too easy, student's boredom and despise psychology; Is too difficult for the student union. And problems should has a hierarchy, in the creation of problem, should as far as possible the design scientific, gradient, a level problem chains, consider good question connection and transition, with methods such as combination, bedding or steps to enhance the overall efficiency of the problem, form a system. Another problem as far as possible to close to the reality or with some interesting, more can attract students' attention arouses student's emotions. For example, in "high voltage technology" course, you need to closely related practice. Introduction of corona discharge, need to consider some engineering application of corona discharge, 
such as chimney electrostatic dust removal problem. Again as in the series inductance and the shunt capacitance in the content, the required capacitance in the same situation at a much lower cost than inductance coil, that is to consider the question in the actual engineering application, and in according to teaching course book, generally only teach electrical performance is good or bad, but don't consider actual economic cost of the project. These can be in the question in the discussion of the establishment and the student guide.

For example, in the course of "engineering electromagnetic field" again a very basic and important knowledge points, that is the Gauss flux theorem of electric field, such as the formula 1 ;

$$
\oiint_{S} \mathrm{E} \cdot \mathrm{d} \mathrm{S}=\frac{q}{\varepsilon_{0}}
$$

In this formula, students seem to be a very simple formula. But it is not easy to let them clear, it is harder to ask students to solve practical problems with it. So when the interpretation can be divided into several small problems. Closed surface integral how to do? For how much is it? Is it electric field intensity for points? What is the direction? On the right side of the equation which local charge? Why can a integral finally into a simple calculation? And so on. If these problems are solved, then the Gauss flux theorem is mastered.

Problems at the same time must take account of the establishment of course characteristics mentioned above. Is very clear to the main knowledge courses, such as some course materials may a big chapter is around a knowledge point of such courses. With one big problem is given priority to, on the basis of the big problems to expand. So a problem to understand clearly, students for this chapter is basically mastered. For the knowledge, concepts more stray course, should adopt a set of a problem. Students understand a question set, the mastery of the chapter, through problem sets inside one by one small problem to master the important concept of stray. In this way, the benefits of students in learning ideas will be very clear, the equivalent of knowledge classification.

The teaching time and the status of teachers are fit. The teaching time and the status of teachers is linked together, because the teacher is just like a party host, on the basis of students' subjective initiative into full play, grasp the rhythm of the class and time. In these two research content, some courses on the number of hours is not much, so appropriate to set up the problems in the teaching content for first requires sufficient preparation is a teacher. Teacher in the whole teaching process should be organizers, guiders, participants, rather than a bystander, need to know when and under what circumstances to enter a process, the next question, the next point. Teachers on the teaching content of teaching should respect students' emotion, lead to check it, but not blindly requires students to answer must be exactly like textbooks. As shown in figure 2 . Grasp the teaching link. This is a preliminary set of teaching links, the late through research, for different courses and then can continue to improve.

The display of multimedia in the teaching of engineering courses is introduced in the paper. And multimedia means in the application of inquiry learning. On the one hand, multimedia can assist teachers to problem cases, according to save the teacher blackboard writing time, convenient control reasonably teaching time; Multimedia auxiliary display, on the other hand, the teaching process, to help teachers to master every step of the teaching schedule progress. Of course in the multimedia display of flow velocity and synchronicity need for further research of teaching. In this way can let students feel every class both informative, and don't think progress too fast, hard to accept.

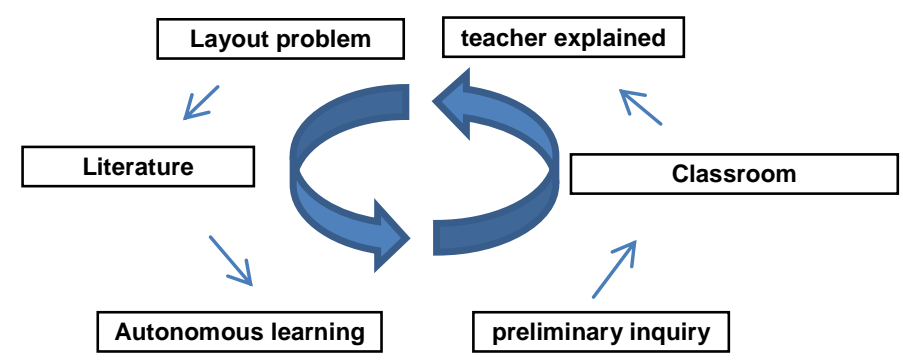

Fig 2. Teaching process

\section{CONCLUSION}

For students, many students of college lack interest for many theoretical classroom teaching and passive learning. And engineering education is not only strong theoretical and abstract, and enterprises, the project is closely linked. Purely lectures often feel unable to get the desired effect. Through the knowledge points one by one and form of problem solving and exploration, to improve students' classroom learning enthusiasm and initiative, and through the problems of cohesion, a ring by ring, to build compact teaching link. The purpose of engineering education is to cultivate the future engineer, in colleges and universities, is not only teach students knowledge, but also to cultivate the students' comprehensive quality, one of the most important things is to find problems independently, the ability to solve the problem. Through class in the problem solving process, cultivate the students' independent study and the ability of independent thinking.

For teachers, teachers in colleges and universities is the classroom teaching on the one hand, on the other hand have the task of scientific research. Through a problem how to think and in the classroom and students to investigate the major aspects of the problem one by one, can be granted by a deeper understanding of professional knowledge, gradually improve their scientific research level and ability. At the same time also can supervise and urge teachers closely contact with enterprise, understand the actual engineering projects.

\section{ACKNOWLEDGMENT}

This study was sponsored by the research project of Three Gorges University under contract no. J2014014.

\section{REFERENCES}

[1] Huang Ping, Liang Xiaobing, Han Kunlun. "Multimedia technology in the curriculum teaching, the application of high voltage technology," China power education, vol. 111, pp. 66-67, April 2008. 
[2] Piao Jishan."The traditional teaching method with modern teaching method optimization integration analysis," Tonghua normal university journal, vol. 30, pp.104-107.May 2009.

[3] Li Shaodong, He Cui, Ma Lili. "Application of project teaching method in the teaching of high voltage technology in Higher Vocational Colleges," China power education, vol.19, pp.67-68. 2010.
[4] Ni Youyuan, Bao Xiaohua, Zhang Xue." Engineering electromagnetic field research course teaching reform," China power education, vol. 194, pp.73-74.July 2011.

[5] Lin Jianjun. "Teaching reform of high voltage technology course," China power education, vol.125, pp. 81-82. 2008.

[6] Gu Hong."Some understanding of inquiry teaching," Adult education, vol. 264, pp.77-78.January 2009. 